\title{
O Papel das Experiências de Consumo na Construção da Imagem das Marcas: Um Estudo nas Companhias Aéreas
}

\author{
The Role of Consumer Experiences in Building the image of brands: A \\ Study in Airlines
}

\section{El papel de las experiencias de los consumidores en la construcción de la imagen de las marcas: A Study in Aerolíneas}

\author{
Ana Iris Tomás Vasconcelos ${ }^{1}$ \\ Diego de Queiroz Machado ${ }^{2}$ \\ Silvio Romero de Almeida ${ }^{3}$ \\ Danielle Miranda de Oliveira Arruda ${ }^{4}$ \\ Fátima Regina Ney Matos ${ }^{5}$
}

\begin{abstract}
Resumo: 0 presente estudo analisa o papel das experiências de consumo na construção da imagem das marcas, a partir da identificação dos pensamentos, sentimentos e ações oriundas das experiências de consumo com as companhias aéreas, e dos tipos de associações que o consumidor faz de tais marcas. Para tanto, utilizou-se uma variação da técnica qualitativa do incidente crítico, que considera aquelas experiências lembradas que tenham se destacado na percepção do consumidor. Foram entrevistados dez usuários dos serviços aéreos, empregando-se formulário semiestruturado em dois blocos: descrição das experiências com as companhias aéreas e informações sobre a imagem das marcas das companhias aéreas. Os dados analisados permitem afirmar que pensamentos, sentimentos e ações oriundas das experiências de consumo tornam-se importantes elementos na formação da imagem das marcas das companhias aéreas. Observou-se que o estado emocional dos pesquisados, resultado de sua interação com os atributos do serviço presentes na experiência, tende a influenciar seus comportamentos de compra futuros, dando indícios da relação entre imagem da marca e sua preferência. Os consumidores utilizam principalmente os atributos do serviço para construir sua percepção sobre as marcas das companhias aéreas.
\end{abstract}

Palavras-chave: Experiências de consumo. Imagem de Marca. Setor aéreo. Incidente crítico.

Abstract: Studies on brand and consumer experience gained emphasis from the twentieth century, however the relationship between these themes still has gaps. Therefore, this study examines the role of consumer experiences in building the brand image through the identification of thoughts, feelings and actions arising from consumer

1 Doutoranda do Programa de Pós-Graduação em Administração de Empresas da Universidade de Fortaleza E-mail: arairistv@hotmail.com

2 Doutorando do Programa de Pós-Graduação em Administração de Empresas da Universidade de Fortaleza. E-mail: diegoqueirozm@yahoo.com.br

3 Doutorando do Programa de Pós-Graduação em Administração de Empresas da Universidade de Fortaleza.E-mail: sylvioalmeida@hotmail.com

4 Professora titular do Programa de Pós-Graduação em Administração de Empresas da Universidade de Fortaleza. Email: danielle@unifor.br

5 Coordenadora e professora titular do Programa de Pós-Graduação em Administração de Empresas da Universidade de Fortaleza. E-mail: fneymatos@unifor.br 
experiences with airlines, and the types of associations that the consumer makes such marks. Therefore, a variation of qualitative critical incident technique was used, considering those remembered experiences that have excelled in consumer perception, interviewing ten users of air services, based on a two parts semi-structured form: description of experiences with airlines and information about the image of the brands of airlines. The analyzed data have revealed that thoughts, feelings and actions arising from consumer experiences become important elements in shaping the perception of brands of airlines. Through the consumption experience, consumers mainly use the service attributes to build their perception of the marks of the airlines. These attributes are used either directly as to support other types of associations such as those related to company size.

Keywords: Consumer Experiences. Brand Image. Airline Industry. Critical incident.

Resumen: Este estudio analiza el papel de las experiencias de consumo en la construcción de la imagen de las marcas de la identificación de los pensamientos, sentimientos y acciones a partir de las experiencias de los consumidores con las compañías aéreas, y los tipos de asociaciones que el consumidor hace tales marcas. Por lo tanto, se utilizó una variación técnica cualitativa del incidente crítico que considera esas experiencias recordadas que se han destacado en la percepción del consumidor. Entrevistamos a diez usuarios de los servicios aéreos, mediante el formulario semi estructurado en dos partes: descripción de experiencias con las compañías aéreas y la información acerca de la imagen de las marcas de las compañías aéreas. Los datos analizados se han puesto de manifiesto que los pensamientos, sentimientos y acciones de las experiencias de los consumidores son elementos importantes en la formación de la imagen de las marcas de las compañías aéreas. Se observó que el estado emocional de los encuestados, el resultado de su interacción con los atributos de estos experiencia operando, tiende a influir en su comportamiento de compra futura, dando evidencia de la relación entre la imagen de marca y su preferencia entre. Los consumidores utilizan principalmente los atributos de servicio para construir su percepción de las marcas de las aerolíneas.

Palabras clave: Experiencias de consumo. La imagen de marca. La industria de las aerolíneas. Incidentes críticos.

\section{INTRODUÇÃO}

A partir da segunda metade do século XX, quando as pesquisas em marca começaram a ganhar força, seu foco principal residiu na investigação de seus efeitos no comportamento dos consumidores, geralmente representados por modelos pragmáticos (Keller \& Lehmann, 2006). Tais pesquisas, como as de Banks (1950), Dolich (1969), Bird, Channon e Ehrenberg (1970), Sheth e Park (1974) e Raj (1985), investigavam principalmente os elementos que levavam a um comportamento de fidelidade às marcas por parte dos consumidores, considerando as preferências pessoais, a frequência de uso do bem e até mesmo a sua popularidade. Outros trabalhos, que davam uma abordagem mais sociológica às relações entre consumidores e marcas, como o de Schenk e Holman (1980), Hirschman (1986) e Lee (1990), e consideravam os aspectos simbólicos desta relação são, desde então, mais escassos.

Recentemente, investigações relativas aos efeitos das marcas no comportamento dos consumidores têm incorporado elementos dessa abordagem sociológica e simbólica, como a de Pyun, Kwon e Lee (2009), Aggarwal e McGill (2012) e Puligadda, Ross Jr. e Grewal (2012). Contudo, pela aplicação prioritária de metodologias quantitativas nessas pesquisas, que acabam por favorecer a elaboração de modelos generalistas, voltados para a representação dos efeitos dos elementos de marca no comportamento dos consumidores, negligencia-se o processo de construção dessa imagem na mente dos consumidores. Além disso, há que se considerar a influência de aspectos culturais neste processo de construção de imagem, como os presentes nas 
pesquisas de Izberk-Bilgin (2012) e Leite, Winck e Zonin (2012), que são mais bem percebidos em investigações de cunho qualitativo, já que estas permitem uma análise aprofundada do fenômeno, em termos de causa, desenvolvimento e efeito.

Em complemento, outro elemento que também merece apreciação nesta relação entre o consumidor e os elementos de marca consistem na própria experiência de consumo existente. Como apontado por Schmitt, Zarantonello e Brakus (2009) e Schembri, Merrilees e Kristiansen (2010), a experiência afeta não apenas a satisfação do consumidor, mas a sua lealdade, que direta e indiretamente é construída com base em associações dessas experiências com aspectos simbólicos da marca.

Tendo em vista que não foram encontrados trabalhos que abordassem os constructos experiência de consumo e imagem da marca de forma conjunta, esta pesquisa se propõe a avançar nas investigações anteriormente realizadas no campo do comportamento do consumidor, considerando o papel das experiências de consumo na construção da imagem das marcas. Para tanto, identifica os pensamentos, sentimentos e ações oriundas das experiências de consumo com as companhias aéreas, bem como identifica os tipos de associações que o consumidor faz de tais marcas.

Desse modo, optou-se pela realização desse estudo no mercado das companhias aéreas, setor cuja importância e características fazem com que seja constantemente campo empírico de pesquisas (Alarcón \& Gil-Lafuente, 2012; Imankhan, Fakharyan \& Feyzabadi, 2012). O relatório Aviation: benefits beyond borders, produzido pelo Air Transport Action Group - ATAG e pela Oxford Economics no ano de 2012, demonstra a representatividade deste campo de estudo. Somente na América Latina e no Caribe o setor de aviação mantém mais de quatro milhões de postos de trabalho e gera mais de US\$ 107 bilhões em Produto Interno Bruto (PIB). As previsões para a América Latina e o Caribe indicam que o número de passageiros deverá quase triplicar de 145,9 milhões em 2010 para 438,9 milhões em 2030. Nesse período, está previsto que o volume de carga aumentará a uma taxa de $6,1 \%$ ao ano.

Em relação à sua metodologia, é empregada uma variação da técnica qualitativa do incidente crítico, desenvolvida por Flanagan (1973). A busca por artigos realizada nas bases SciELO, ANPAD e Spell indicou uma tendência de baixa utilização da técnica do incidente crítico no Brasil. Na base eletrônica SciELO, identificou-se vinte e um artigos informando a utilização da técnica, no período entre os anos 2000 a 2012. Destes artigos, dezenove abordam temas relacionados à área da Saúde e dois são da área de Gestão Mercadológica, tratando especificamente de estudos sobre o nível de satisfação do consumidor.

Diante do exposto, espera-se que este trabalho possa contribuir ao procurar compreender o papel das experiências de consumo na construção da imagem de marcas, a partir de uma metodologia pouco utilizada em outras pesquisas do campo, colaborando, desta forma, com resultados não alcançados em trabalhos anteriores e que, deste modo, acabe por promover um avanço nas discussões sobre tais temas. 


\section{A CONSTRUÇÃO DA IMAGEM DAS MARCAS}

Biel (1993) lembra que qualquer expectativa de sucesso de uma marca depende do comportamento do consumidor. E o comportamento do consumidor é, em sua raiz, impulsionado pela percepção de uma marca.

Percebe-se que, do ponto de vista do consumidor, as marcas podem ser entendidas como uma síntese das experiências reais e virtuais, objetivas e subjetivas, vividas em relação ao produto, serviço, empresa, instituição ou, mesmo, pessoa (Sampaio, 2002). Ao contemplar as impressões dos consumidores sobre a marca, Sampaio (2002) dá indícios da relação entre a imagem das marcas e as experiências de consumo, o que é reforçado por Keller e Machado (2006, p. 36), ao afirmarem que "a força de uma marca está no que os clientes aprenderam, sentiram, viram e ouviram sobre ela como resultado de suas experiências ao longo do tempo".

Por definição, a imagem de uma marca corresponde a um conjunto de atributos e associações que os consumidores conectam à marca (Biel, 1993). Estas associações evocadas podem ser percepções específicas de atributos tangíveis/funcionais, como velocidade, preço premium, ou o número de voos por dia. Podem também ser percepções mais emocionais, como excitação, confiabilidade, diversão e inovação (Biel, 1993).

Dentre os modelos que tratam da construção da imagem das marcas (Biel, 1993; Aaker \& Joachimsthaler, 2000; Keller \& Machado, 2006), o presente trabalho adota o de Keller (1993), haja vista o pioneirismo do autor, em conectar as associações subjetivas do consumidor à imagem das marcas. Para Keller (1993), os diferentes tipos de associações que os consumidores desenvolvem quanto às marcas determinarão a imagem que tais marcas terão em sua memória. Assim, as associações de marca são nós que contêm significados e que se conectam às marcas, podendo ser classificadas quanto aos atributos, benefícios e atitudes (Keller, 1993). A Figura 1 resume as proposições de Keller (1993) sobre as dimensões da imagem de uma marca.

As associações à marca podem ser classificadas em três categorias principais de escopo: os atributos, os benefícios e as atitudes. Os atributos são características descritivas que podem estar ou não relacionadas ao produto ou serviço. Keller (1993) defende que existem quatro tipos principais de atributos que não estão relacionados ao produto, que são as informações sobre preço, a aparência de embalagem ou do produto, a imagem do usuário, que corresponde ao tipo de pessoa que utiliza o produto ou serviço e, por último, a imagem de uso, ou seja, onde e em que tipos de situações o produto ou serviço é usado.

Quanto aos benefícios, esses são os valores pessoais ou sociais que o consumidor obtém na compra de um produto ou serviço (Keller, 1993). De acordo com o autor, os benefícios podem ser distinguidos em três categorias. A primeira, benefícios funcionais, são as vantagens mais intrínsecas de consumo do produto ou serviço e geralmente correspondem a atributos relacionados ao produto. Os benefícios experimentais se relacionam com o que o consumidor sente ao usar o produto ou serviço e também, normalmente, corresponde aos atributos relacionados ao produto. Estes benefícios satisfazem necessidades, como o prazer sensorial, 
variedade e estimulação cognitiva. Já os benefícios simbólicos são as vantagens mais extrínsecas do consumo do produto ou serviço. As atitudes correspondem ao último escopo de associações relacionadas à marca proposto por Keller (1993). Para o autor, as atitudes correspondem às avaliações globais dos consumidores de uma marca.

Figura 1 - Dimensões da imagem da marca

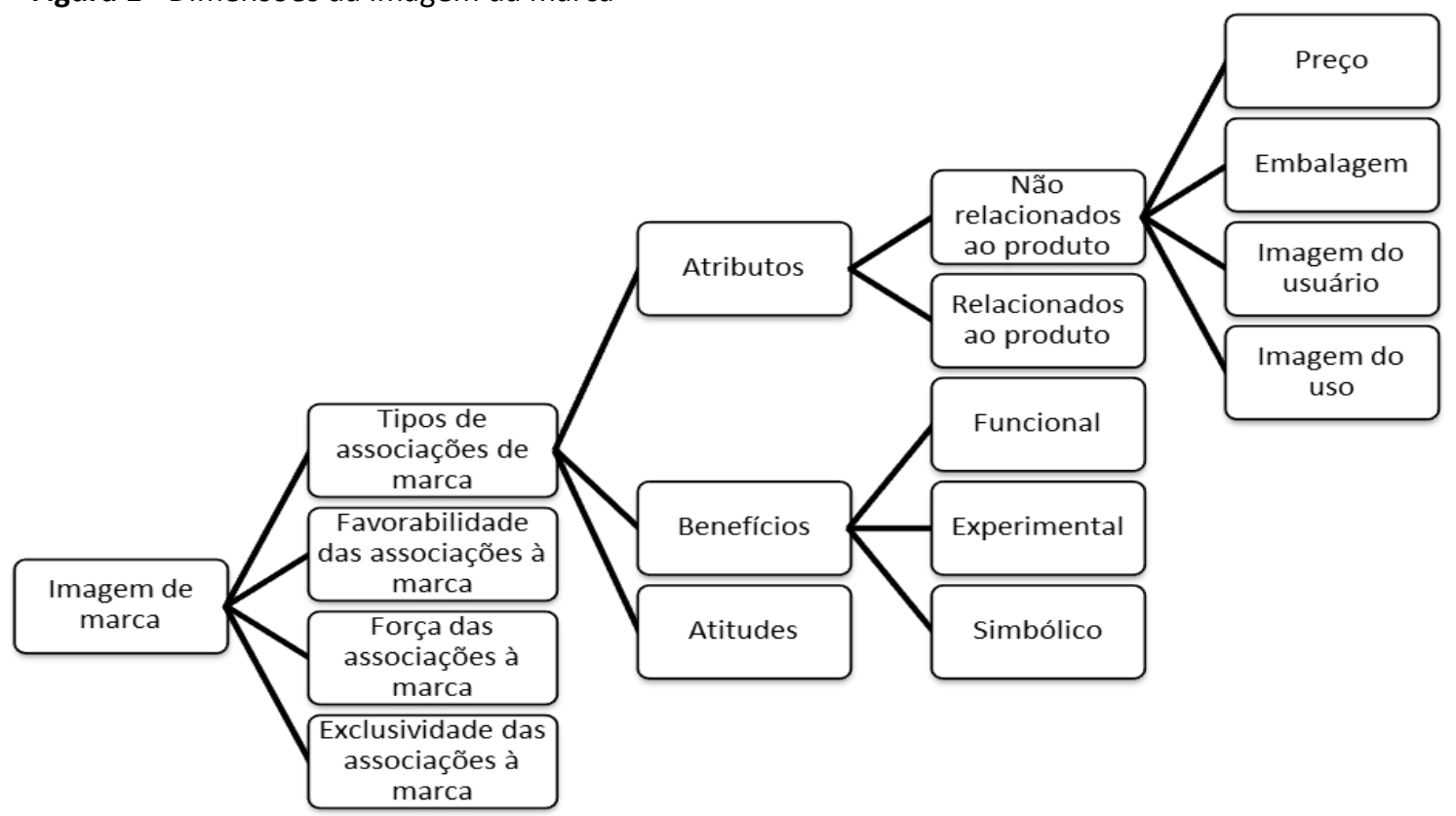

Fonte: Adaptado de Keller (1993)

Completando seu modelo, Keller (1993) lembra que as associações ligadas a uma marca podem variar de acordo com a favorabilidade, força e exclusividade de tais associações. A favorabilidade se refere à forma como a marca é avaliada, podendo depender do contexto e variar de acordo com os objetivos específicos dos consumidores nas suas decisões de compra ou consumo (Keller, 1993). Já a força da associação é quão uma imagem está ligada à marca e depende de como as informações entram na memória dos consumidores (codificação) e como ela é mantida como parte da imagem de marca (armazenamento). Por fim, as associações ligadas à marca podem ser compartilhadas com outras marcas concorrentes, ou seja, podem ser exclusivas ou não a uma marca.

\section{A EXPERIÊNCIA DE CONSUMO}

No campo dos estudos do comportamento do consumidor, uma experiência é, sobretudo, um acontecimento pessoal, muitas vezes com importante significado emocional, fundada sobre a interação com os estímulos que são os produtos ou serviços consumidos (Holbrook \& Hirschman, 1982).

Brakus, Schmitt e Zarantonello (2009) propõem um conceito mais detalhado de experiência de consumo, que é o adotado no presente estudo. Os autores definem experiência de consumo 
como sensações, sentimentos, cognições e respostas comportamentais proporcionados pela relação com um estímulo da marca. Complementam seu raciocínio, afirmando que os veículos da experiência dependem do meio o qual o consumidor obtém uma experiência pessoal ou social, ou seja, pode ser através de um produto, um ambiente de varejo, a internet ou uma marca.

Vale ressaltar, entretanto, que a literatura ainda indica os serviços como outro veículo da experiência. A experiência de serviço ocorre quando um consumidor tem alguma sensação ou aquisição de conhecimento resultante de um nível de interação com diferentes elementos de um contexto criado por um provedor de serviços (Gupta \& Vajic, 1999). Tendo em vista as características específicas dos serviços, Bitner et al. (1997, p. 193) propõem que as experiências de consumo nos serviços são o resultado das interações entre "a organização, seus sistemas/processos relacionados, seus funcionários e os consumidores".

Apesar da semelhança entre os diferentes tipos de experiência, percebe-se, com base na literatura consultada (Gupta \& Vajic, 1999; Brakus, Schmitt \& Zarantonello, 2009; Kapferer, 1992) que, no caso da experiência com a marca, a percepção do consumidor é fruto de um esforço planejado da organização em construir a identidade de sua marca, enquanto os demais tipos de experiência não fazem parte, necessariamente, destes esforços de construção de marca por parte da empresa.

Diante dos diferentes tipos de veículos que podem desencadear as experiências, o foco para orientar este trabalho é o estudo das experiências de consumo nos serviços aéreos lembradas por seus usuários (Arnould et al., 2002).

Hirschman e Holbrook (1982a) diferenciam o consumo hedônico em contraste ao utilitário. O consumo hedônico designa as faces do comportamento que se relacionam com os aspectos multisensoriais, emotivos e de fantasia que o consumidor experimenta com os produtos. Ao utilizar a perspectiva hedonista do consumo, os produtos deixam de ser vistos como entidades objetivas para serem considerados símbolos subjetivos, sendo valorizados pelo o que representa, não com o que ele é.

Por fim, ressalta-se que durante a etapa da experiência de consumo lembrada (Arnould et al., 2002), o que diferenciará a experiência extraordinária de uma ordinária será o encantamento do consumidor, se dá através da surpresa, prazer, divertimento e lembrança que o consumidor guarda na memória (Hanefors \& Mossberg, 2003).

\section{METODOLOGIA DE ESTUDO}

Esse estudo se caracteriza como exploratório, descritivo e de natureza qualitativa. A técnica de pesquisa escolhida para sua condução é uma variação da técnica do incidente crítico que busca explorar pensamentos, sentimentos e comportamentos de ocorrências significantes identificadas pelo respondente (Chell, 1998).

Apesar de pouco explorada na área de administração de empresas no Brasil (Moreira \& Trocolli, 2013), a técnica do incidente crítico pode ser muito útil em pesquisas de marketing por 
permitir que o pesquisador capte fatores culturais, valores, experiências, sentimentos, emoções dos sujeitos que vivenciam uma situação (Ribeiro et al., 2012).

Considera-se, portanto, como incidentes críticos aquelas experiências de consumo lembradas que tenham se destacado na percepção do consumidor (Cougo, 2001). Foram entrevistadas dez pessoas, selecionadas por terem lembranças de alguma experiência marcante de consumo com companhias aéreas. Os dados foram coletados por meio de entrevistas, realizadas individualmente, com base em formulário semiestruturado, cujas questões norteadoras foram organizadas em dois blocos: (a) descrição das experiências com as companhias éreas; e (b) informações sobre a imagem das marcas das companhias aéreas. A quantidade das entrevistas respeitou o critério de saturação dos dados. Depois da coleta das entrevistas, os relatos foram tratados por um processo de análise de conteúdo (Bardin, 2002; Chizzotti, 2006), identificando-se os pensamentos, sentimentos e comportamento decorrentes das experiências de consumo.

Visando à objetividade do estudo, três pesquisadores devidamente capacitados coletaram e analisaram os dados de forma independente. Vale salientar que, embora a classificação das categorias do estudo tenha utilizado inicialmente a base teórica, durante a análise dos dados foram consideradas outras categorias que emergiram durante as entrevistas. Tal procedimento apóia-se na proposição de Stauss (1993) de que as principais categorias de classificação dos incidentes críticos podem ser deduzidas a partir de modelos teóricos ou formadas com base na interpretação indutiva. No caso do presente estudo, as categorias de análise tiveram tanto base teórica como indutiva.

A base teórica adotada para classificar as experiências com as companhias aéreas foi proposta por Chell (1998). A análise dos incidentes críticos e as categorias de análise da marca foram adaptadas a partir do modelo proposto por Keller (1993), apresentado no Quadro 1.

Quadro 1 - Categorias de análise da experiência e imagem da marca utilizadas na pesquisa

\begin{tabular}{|c|c|c|}
\hline & Dimensões & Categorias \\
\hline \multirow{6}{*}{ Experiência } & \multirow{2}{*}{ Pensamento } & Pensamento Positivo \\
\hline & & Pensamento Negativo \\
\hline & \multirow{2}{*}{ Sentimento } & Sentimento Positivo \\
\hline & & Sentimento Negativo \\
\hline & \multirow{2}{*}{ Comportamento } & Comportamento Positivo \\
\hline & & Comportamento Negativo \\
\hline \multirow{8}{*}{ Imagem da Marca } & \multirow{4}{*}{ Atributo } & Atributo do Serviço \\
\hline & & Atributo Preço \\
\hline & & Atributo Imagem do Usuário \\
\hline & & Atributo Imagem de Uso \\
\hline & \multirow{3}{*}{ Benefícios } & Benefício Funcional \\
\hline & & Benefício Experimental \\
\hline & & Benefício Simbólico \\
\hline & Atitudes & Atitudes \\
\hline
\end{tabular}

Fonte: Elaborado pelos autores, com base em Chell (1998) e Keller (1993) 
Para o tratamento dos dados, foi utilizado o software Atlas/ti, versão 6.0, que permitiu classificar e conectar as respostas. Nesta classificação, houve o agrupamento dos dados captados na narrativa de cada entrevista, em temas recorrentes e alinhados às categorias de análise da experiência e da imagem da marca. Por fim, procuraram-se regularidades, aproximações, padrões, significações (Silva, 2005).

\section{RESULTADOS E DISCUSSÃO}

\subsection{Componentes das experiências de consumo}

De acordo com o mapeamento realizado, foram identificadas várias experiências de consumo. Partindo-se da análise dos pensamentos dos respondentes em relação a essas experiências, observou-se a presença de pensamentos tanto positivos quanto negativos. 0 pensamento positivo, explicitado através de expressões como "boa", "diferente" e "especial", se mostrou relacionado a dois fatores: (1) atendimento prestado pela equipe de bordo em situações onde ocorreram problemas técnicos com a aeronave; e (2) boa qualidade dos serviços de bordo ofertados pela companhia aérea.

\footnotetext{
"O suporte, vamos dizer, de atendimento eu achei bom e diferente, depois que resolveu o problema da aeronave. A forma como o comandante informou os procedimentos padrões eu nunca tinha visto antes. Foi assim... Foi um atendimento acho que adequada pra todo mundo" (Entrevistado 6).

"Quando houve a turbulência, fiquei preocupado com meu filho, mas o atendimento da aeromoça foi muito bom. Foi uma experiência especial" (Entrevistado 3).

"O serviço de bordo foi muito bom, a comida era gostosa, era tudo farto, então era uma coisa bem diferente do que a gente tá acostumando no Brasil, então foi uma experiência boa e diferente" (Entrevistado 5).
}

Observou-se que os serviços de bordo remetem não só a pensamentos positivos, mas também a negativos. Os pensamentos positivos são motivados quando o entrevistado percebe variedade e qualidade do que é servido durante a viagem; entretanto, tais pensamentos tornamse negativos, quando estão relacionados à cobrança do lanche durante a viagem.

“É uma experiência muito chata ter que comprar o lanche dentro do avião" (Entrevistado 5)

“Eles chegam logo com a máquina do cartão [...] é uma situação ruim” (Entrevistado 8).

De forma semelhante, experiências motivadas por cancelamentos de voos podem também gerar pensamentos positivos e negativos. Os pesquisados classificaram como 'agradável' a experiência em que a companhia foi além dos procedimentos padrões e lhes prestou total apoio. Encontraram-se, entretanto, pensamentos negativos relacionados às situações de atraso e 
cancelamento de voo, quando o pesquisado não percebeu um atendimento, por parte da companhia, que transmitisse respeito e consideração por seu transtorno diante dessas situações. Neste caso, os pesquisados classificaram as experiências como "desagradável" e "terrível".

\begin{abstract}
"A lembrança que eu tenho de experiência é totalmente negativa, porque a companhia tem mostrado de um ano pra cá muito atraso de voo, e também demonstra falta de foco com o cliente" (Entrevistado 6).

"Bom uma vez eu estava em Fortaleza e teria que retornar pra minha cidade porque no outro dia de manhã eu teria trabalho. Chegando no aeroporto sem aviso prévio eu fui comunicado que o voo havia sido cancelado. Essa falta de aviso prévio pra mim foi uma falta de respeito total com o consumidor. Foi uma situação muito desagradável" (Entrevistado 5).
\end{abstract}

Os elementos que chamaram a atenção dos consumidores, positivos ou negativos, sobrevêm no decorrer de sua experiência de compra e de consumo (Cougo, 2001). Desta forma, a geração do sentimento é influenciada por essas experiências. O sentimento positivo, refletido nas expressões tranquilidade e bem-estar, está relacionado ao bom atendimento prestado por parte da companhia.

\footnotetext{
"Uma viagem que eu fiz com meu filho de três anos [...] E o atendimento que foi dado pra gente naquele momento me deixou muito tranquilo porque o avião passou por uma turbulência, a aeromoça veio sentou do lado dele, porque a poltrona estava vaga, e sentou e colocou o cinto, conversou. Como era a primeira vez que viajava somente eu e ele, a atitude da aeromoça me deixou muito tranquilo" (Entrevistado 3).

"Quando eu vi que tinha perdido o voo, fui até o checkin para explicar a situação, depois a mulher já me mandou com um funcionário deles pro portão de embarque com as minhas malas sem nenhuma burocracia e taxa. Me senti muito bem, muito bem mesmo" ( Entrevistado 1).
}

Já o sentimento negativo, expresso em termos como aflito, cansado e intimidado, está relacionado ao atraso do voo e à cobrança pelo lanche servido a bordo.

\footnotetext{
"Muito cansaço... porque já vinha de um voo internacional aí tinha que pegar um voo de São Paulo pro Rio aí você imagina né, você passa um dia todinho praticamente vem de um voo virado né, sem ter dormido, ainda ter que esperar até sete da noite pra embarcar então realmente é bastante cansativo" (Entrevistado 10).

"Você ter que comprar lanche dentro do avião é uma situação muito chata. Me sinto muito intimidado em solicitar até um copo d'agua porque eles já vem com a máquina do cartão" ( Entrevistado 5)

"Fiquei muito aflito com este atraso do voo. Tinham pessoas me esperando em Buenos Aires, e depois eu estava de férias, queria aproveitar e não sabia quando eu iria chegar lá" (Entrevistado 2).
}

Observou-se que os sentimentos positivos são propiciados à medida que a companhia presta assistência aos consumidores, como providenciando acomodações confortáveis durante a 
espera antes do embarque, acomodação em hotel quando um voo é cancelado, e um atendimento de bordo adaptado às necessidades do consumidor.

A análise dos dados ainda indicou que o estado emocional dos pesquisados, enquanto resultado de sua interação com os atributos do serviço presentes na experiência, parece influenciar em seus comportamentos futuros. O comportamento positivo, explicitado em situações de indicação para amigos e consideração para compras futuras, está relacionado com o bom atendimento prestado aos pesquisados.

"Eu sou sempre muito bem atendido, mas essa situação foi especial porque eu cheguei a perder meu voo, e aí eu acho que depois disso eu sempre indico para meus amigos" (Entrevistado 1).

"Com a experiência que eu tive relacionada ao avião, eu indicaria. Pra mim, ela se torna melhor do que outras" (Entrevistado 8)

"Vou optar pela companhia porque eu sei que eu vou ter um bom atendimento [...] Essa é a questão" ( Entrevistado 3 ).

Os comportamentos negativos encontrados foram considerar a companhia "em última hipótese" ou considerar companhias que apresentem o melhor custo-benefício. Vale salientar que tais comportamentos foram observados quando os consumidores associaram à experiência pensamentos e sentimentos negativos.

\footnotetext{
“Eu penso que é um mal necessário viajar pela companhia porque é a única que me dá a possibilidade de estar aqui no menor tempo possível e com o menor custo. Mas eu sempre fico pesquisando qual a companhia mais barata, porque tenho que viajar toda semana" (Entrevistado 6)

“Como foi uma situação que deixou muito a desejar por parte da companhia eu só volto a viajar nela em última hipótese" ( Entrevistado 5).
}

Em suma, a partir da análise das experiências de consumo nas companhias aéreas, quando caracterizadas em relação aos componentes da metodologia de incidente crítico pensamento, sentimento e comportamento (Chell, 1998) - é possível perceber de que forma esses elementos se fazem presentes em situações de consumo. Ademais, a análise das falas dos respondentes em relação às experiências pressupõe uma interação entre esses elementos e o modelo de construção de imagem de marca, apresentado por Keller (1993). Em relação a esses aspectos de construção de imagem de marca, seus componentes são analisados a seguir.

\subsection{Análise das dimensões da imagem da marca}

Utilizando-se o modelo proposto por Keller (1993), adaptado para serviços, apresentado na Figura 1, esta análise buscou identificar as categorias apresentadas no referido modelo, que são mais associadas à imagem das companhias aéreas. As categorias estudadas são: atributos não 
relacionados ao serviço (preço, imagem do usuário, imagem de uso); atributos relcionados ao serviço; benefícios (funcional, experimental, simbólico); e atitudes.

Em relação aos atributos que não estavam relacionados ao serviço, estes se referiram principalmente às associações quanto ao preço baixo e à imagem de uso. Esta última, de acordo com Keller (1993), corresponde a onde e em que tipos de situações o serviço é usado.

“Ela é uma empresa barata, então o meu foco é o preço" (Entrevistado 5).

"Eu acho muito mais pra voos rápidos, domésticos, eles são muito diretos assim. Até os serviços mesmo que eles oferecem são muito, muito simples" (Entrevistado 7).

Observou-se que, ao associar a companhia aérea a uma modalidade de voo como "rápido" e "doméstico", o consumidor evoca outro atributo também relacionado à imagem da empresa, que é o porte da companhia. Geralmente a imagem de "companhia pequena" está associada a preço mais baixo e pouca qualidade nos serviços. Para caracterizar a qualidade dos serviços, os entrevistados utilizaram os serviços de bordo, atendimento e pontualidade do voo.

"Já fiz um voo, isso a mais tempo atrás entre Uberaba e São Paulo em uma companhia muito pequena que tem, que ainda tem jatinhos pequenininhos, o voo terrivel, então eu falei: bom, vai ser um voo nesse sentido" (Entrevistado 3).

De acordo com Keller (1993), os atributos relacionados ao produto correspondem às suas características descritivas, que, no caso da análise dos serviços, abrange as características da organização desde seus processos ao atendimento dos funcionários (Bitner et al., 1997). Com efeito, foi possível identificar que a imagem das companhias aéreas também está associada ao atendimento que prestam a seus usuários. Vale salientar que o atendimento personalizado traz consigo benefícios simbólicos e experienciais. Ao receber um serviço diferenciado, por parte da companhia aérea, o consumidor percebe como benefício simbólico ser reconhecido e importante, e, consequentemente, isso lhe traz sentimentos de bem-estar e tranquilidade.

"Eu viajei pela mesma companhia aérea para Namíbia e o aeroporto da Namíbia não tem muita estrutura e teve um incêndio lá e eu não pude voltar pra África do Sul e eles me deram toda a assistência assim de passar o dia, deram hotel e tudo bem... Foram bem atenciosos, mas não foi ligado à empresa aérea o problema foi mais ligado ao aeroporto. Mesmo assim eles assumiram a responsabilidade e cuidaram muito bem da gente, foi agradável [...] Essa situação foi especial" (Entrevistado 1).

Observou-se também que este tipo de atendimento ganha relevância no caso da modalidade da viagem (a trabalho, lazer, sozinho, com família, etc.) e, quando o consumidor se encontra diante de um problema, como ter perdido o voo. Em viagens com a família, percebe-se que o atendimento personalizado por parte da companhia torna-se mais relevante para a construção da imagem da marca que os demais serviços. É o caso de um dos entrevistados, que viajava somente com o filho de três anos, pela primeira vez. Durante uma turbulência, uma das 
comissárias de bordo sentou-se ao lado do filho e prestou-lhe toda a atenção. Segundo um dos entrevistados:

\begin{abstract}
"Acho que recente a que mais me marcou porque foi familiar, porque foi uma coisa com meu filho diferente às vezes de uma viagem de negócio que você ta mais preocupado se tem uma comodidade, ou uma tomada pro laptop, se você tem acesso a internet, a Gol tem a disponibilidade de você acessar a internet e tudo né, mas acho que essa marcou mais. [...] Tenho uma imagem muito boa... de um atendimento ótimo" (Entrevistado 3).
\end{abstract}

Alguns consumidores também utilizaram o atendimento para caracterizar as companhias aéreas como "mecânica no atendimento" e que "não respeita o consumidor".

\begin{abstract}
"Quando eu penso na companhia, a minha experiência pessoal foi de um atendimento de uma prestação de serviço no mínimo atenciosa na necessidade né. [...] A gente já tinha viajado por outra companhia também, mas observamos uma coisa mais mecânica de atendimento, um próprio serviço de produção, uma coisa bem multimídia" (Entrevistado 2).
\end{abstract}

\begin{abstract}
"Chegando ao aeroporto sem um aviso prévio eu fui comunicado que o voo havia sido cancelado e que eles iam me realocar se houvesse oportunidade. Isso me deixou muito, assim contrariado da minha dificuldade por conta do compromisso que eu tinha no trabalho, ou seja, essa falta de aviso prévio pra mim foi uma falta de respeito total com o consumidor naquele momento" (Entrevistado 5).

"Nada, eles não deram nenhuma satisfação, eles não falam nada né, [...] o pessoal de avião não fala com os mortais que somos nós né. Mesmo eles fazendo aquela brincadeirinha lá de fingir, como o pessoal que usa aquelas máscaras e o pessoal finge que presta atenção. [...] Não há comunicação" (Entrevistado 8).
\end{abstract}

Também foi possível perceber que os entrevistados ainda utilizaram as atitudes, ou seja, avaliações globais (Keller, 1993), para descreverem as companhias aéreas como "empresa confiável" e "empresa confortável". Para associar a marca ao conforto, o entrevistado utiliza os atributos das aeronaves para tornar tangível sua percepção, como as características dos assentos e o serviço de bordo. Já para associar uma empresa como confiável, o atributo utilizado foi a pontualidade do voo, bem como as experiências anteriores com a companhia.

Neste contexto, mesmo não sendo considerada, a princípio, como categoria desta análise, a dimensão de exclusividade das associações à marca (Keller, 1993) se mostrou relevante na análise das experiências dos entrevistados. Assim, percebeu-se que a imagem das marcas das companhias aéreas tende a ser exclusiva, quando se relaciona ao atributo atendimento personalizado, bem como quando a companhia atende ou supera as expectativas dos usuários. Vale esclarecer que o atendimento personalizado foi observado quando a empresa adaptou seu atendimento às necessidades individuais de cada passageiro.

Neste caso, verificou-se como consequência desta relação que os pesquisados demonstraram interesse em continuar utilizando os serviços desta companhia aérea. 
"Eles atenderam muito, muito bem. [...] Por que às vezes pesa mais você ter um problema e você ser atendido, e você ser... ser solucionado, ter aquele problema solucionado do que uma questão de conforto, entendeu? [...] Eu iria novamente" (Entrevistado 7).

"Ah, eu tenho uma imagem muito boa. [...] Porque eu vou falar: bom eu sei que eu vou ter um preço justo né e um atendimento... Eh, eu acho que ótimo né pelas vezes que eu tive oportunidade de viajar por eles e eu fui muito bem acolhido por toda a companhia, então é a primeira que eu faço essa seleção. Acho que hoje em dia esse é o meu comportamento" (Entrevistado 3).

Nos casos em que esta relação entre atendimento personalizado e expectativas dos usuários não se fez presente, entretanto, observou-se uma dificuldade dos entrevistados na construção de uma imagem de exclusividade da companhia aérea. Dessa forma, entende-se que a consequente dificuldade de diferenciação, através da marca, neste setor pode ser superada mediante uma concentração de esforços estratégicos das companhias nestes elementos.

\subsection{Relações entre experiências de consumo e dimensões de imagem de marca}

Tendo em vista analisar o papel das experiências de consumo na construção da imagem das marcas, nesta última etapa de análise dos dados coletados, buscou-se identificar as relações entre os componentes das experiências de consumo (pensamento, sentimento e comportamento) e as dimensões de imagem de marca (atributos, benefícios e atitudes). A Figura 2 representa as relações identificadas.

Figura 2 - Relações entre experiências de consumo e imagem da marca das companhias aéreas

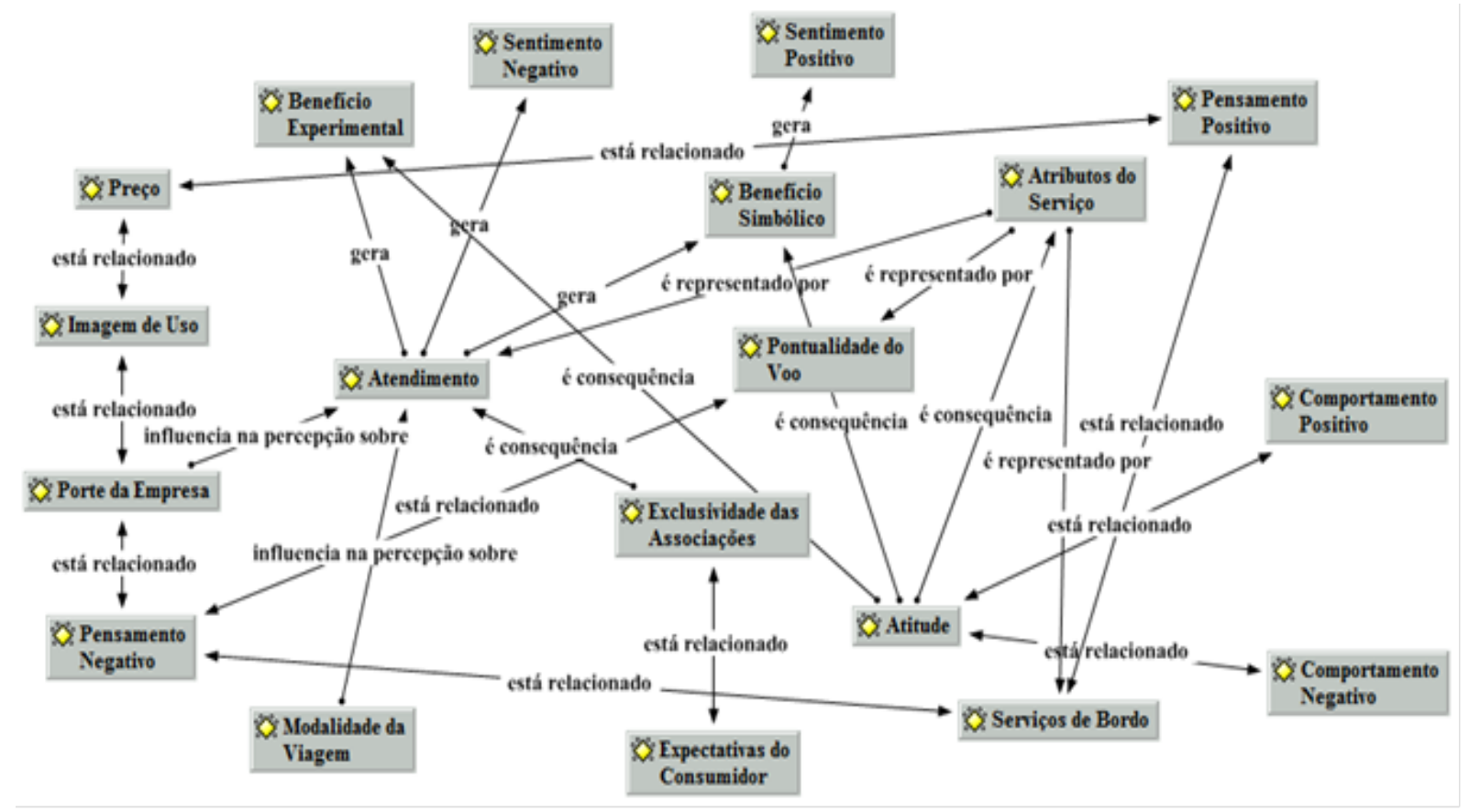

Fonte: Dados da pesquisa 
Em um primeiro momento, observa-se que os atributos dos serviços se constituem como elemento central na influência das experiências de consumo na construção da imagem de marca. Esses atributos, que surgem representados por aspectos de atendimento, serviços de bordo e pontualidade do voo, são responsáveis por gerar nos consumidores sentimentos ora negativos, ora positivos. Neste sentido, sua influência na promoção de sentimentos negativos aparece em situações em que esses atributos, principalmente os de atendimento, são apresentados para os consumidores de uma forma mecânica. Em contrapartida, quando esses atributos são percebidos como favoráveis para o bem-estar dos consumidores, eles acabam por gerar benefícios simbólicos e experienciais, os quais, por sua vez, promovem sentimentos positivos nos consumidores do serviço.

Ainda em relação aos atributos dos serviços percebidos na análise das experiências dos consumidores de companhias aéreas, um elemento que emerge na fala dos entrevistados e parece ter um papel fundamental na percepção destes últimos sobre os atributos do serviço é o porte da empresa. Esse aspecto aparece ainda em situações e citações de atributos não relacionados ao serviço, como preço e imagem de uso. Nestes casos, o porte da empresa cria na mente dos consumidores expectativas em relação a esses dois elementos. Dessa forma, é possível afirmar que uma análise desses atributos que desconsidere a imagem que os consumidores têm das companhias prestadoras de serviços seria uma análise limitada.

Além disso, outro aspecto não apresentado no modelo de Keller (1993), mas que também emerge das experiências relatadas pelos entrevistados como referente à percepção do atendimento é a modalidade da viagem. Em outras palavras, significa afirmar que, dependendo do tipo de modalidade de viagem do consumidor (férias, lazer, trabalho, sozinho, com família, etc.), este apresenta uma percepção diferente do atendimento das companhias.

Também como elemento relacionado ao atributo de atendimento do serviço, surge o aspecto de exclusividade das associações. Essa exclusividade das associações foi percebida quando os entrevistados relataram possuir uma determinada imagem da companhia aérea utilizada e se essa imagem se estendia ou não para outras empresas. Geralmente essa exclusividade da imagem da marca se fez presente em situações em que a expectativa inicial em relação à companhia foi superada de forma positiva.

Finalmente, as dimensões de atitudes relativas à imagem de marca, que apresentaram uma forte relação com os aspectos comportamentais das experiências de consumo, emergiram nas falas dos entrevistados como consequência dos atributos do serviço e dos benefícios percebidos pelos consumidores nas experiências relatadas.

\section{CONSIDERAÇÕES FINAIS}

Depreende-se, com base nos dados analisados, que os pensamentos e sentimentos oriundos das experiências de consumo tornam-se importantes elementos na formação da imagem das marcas das companhias aéreas, bem como que esta imagem parece influenciar o 
comportamento de compra futuro do consumidor. Para ilustrar tal afirmação verificou-se que pensamentos positivos associados à experiência, como "boa e diferente" e "especial" geraram nos consumidores sentimentos de "tranquilidade" e "bem-estar". Como consequência, os consumidores pesquisados demonstraram um comportamento positivo em relação à empresa, como considerá-la para viagens futuras e indicá-la para amigos.

De forma semelhante, foi possível perceber que pensamentos negativos como "desagradável" e "terrível" geram como sentimento a "aflição" e como comportamento a consideração da marca apenas em "última hipótese" por parte dos pesquisados.

Assim, o ciclo - pensamentos, sentimentos e ações - contribui para criar no consumidor determinadas imagens da marca, que, no caso de uma experiência positiva, foram de uma empresa "confiável", "confortável" e, no caso de uma experiência negativa, de uma empresa que "não respeita o consumidor" e que possui "atendimento mecânico".

Vale salientar, entretanto, que experiências inicialmente negativas, como um cancelamento ou atraso do voo, podem desencadear um ciclo que contribui para formar uma imagem positiva da companhia. Nestes casos, percebe-se que as empresas agem de forma a atenuar o problema, por meio de ações que demonstram respeito e preocupação com o bemestar do consumidor.

Sobre os tipos de associações relacionadas às companhias aéreas, verificou-se que os consumidores utilizaram principalmente o atendimento. Este tipo atributo ganha relevância no caso da modalidade da viagem (a trabalho, lazer, sozinho, com família, etc.) e quando o consumidor se encontra diante de um problema, como ter perdido o voo. Ainda foi possível perceber que aliado ao atendimento do serviço surge o aspecto de exclusividade das associações. Geralmente essa exclusividade da imagem da marca se fez presente em situações em que a expectativa inicial em relação à companhia é superada de forma positiva através de um atendimento personalizado.

A análise dos dados apresenta algumas implicações gerenciais. Primeiro, é possível afirmar que, através da experiência de consumo, os consumidores utilizam principalmente os atributos do serviço para construir a imagem das marcas das companhias aéreas. Tais atributos tanto são usados de forma direta como para apoiar outros tipos de associações como as relacionadas ao porte da companhia.

O estudo também evidenciou que as emoções advindas da experiência de consumo pareceram ter marcado fortemente a memória do consumidor (Holbrook \& Hirschman, 1982). Durante as entrevistas, as pessoas demonstraram facilidade em detalhar as experiências que tiveram com as companhias aéreas, todas compreendidas no período de um a cinco anos. Foi possível ainda verificar a importância do comportamento proativo por parte das companhias no que se refere à gestão das experiências de seus consumidores, haja vista seu importante papel na avaliação da experiência por parte do consumidor. 
Também é importante ressaltar que o estado emocional dos pesquisados, resultante de sua interação com os atributos do serviço durante a experiência, parece influenciar em seus comportamentos futuros, como no caso de preferir ou não a marca em escolhas futuras.

Apesar dos achados da pesquisa não permitirem generalização, dada sua natureza qualitativa (Malhotra, 2001), acredita-se que a explicitação da relação entre experiência de consumo e imagem da marca e, mais especificamente, da importância da gestão desta relação por parte das organizações, possa ser útil não só para o setor estudado, mas para o segmento de serviços de uma forma geral, caracterizado por sua forte concorrência.

Por fim, fica como sugestão, para pesquisas posteriores, a aplicação da técnica do incidente crítico para estudar experiências de consumo que possuam características diversas, em relação às etapas da experiência (Arnould et al., 2002) e ao setor estudado, buscando sua relação com a imagem das marcas. Acredita-se que isso levará a uma melhor compreensão da natureza da experiência de consumo, seu papel na construção da imagem das marcas e, consequentemente, no comportamento do consumidor.

\section{REFERÊNCIAS}

Aaker, D. \& Joachimsthaler, E. (2000) Brand Leadership. Free Press: London.

Aggarwal, P. \& Mcgill, A. L. (2012) When brands seem human, do humans act like brands? Automatic behavioral priming effects of brand anthropomorphism. Journal of Consumer Research, 39(2), pp. 307-323.

Alarcón, C. N. \& Gil-Lafuente, J. (2012) Customer experience assessment: forgotten effects. Journal of Computational Optimization in Economics and Finance, 4(2), pp. 77-88.

Arnould, E., Price, L. \& Zinkhan, G. (2002) Consumers. McGraw-Hill, New York.

ATAG - Air Transport Action Group (2012) Aviation: benefits beyond borders report. Disponível em www.aviationbenefitsbeyondborders.org. Acesso em 15 de agosto de 2013.

Banks, S. (1950) The relationships between preference and purchase of brands. Journal of Marketing, 15(2), pp. 145-157.

Bardin, L. (2002). Análise de conteúdo. Edições 70: Lisboa.

Biel, A. L. (1993) Converting image into equity. In: Aaker, D. A. \& Biel, A. (org.) Brand equity and advertising - advertising's role in building strong brands. Lawrence Erlbaum Associates Publishers, Hillsdale, NJ.

Bird, M., Channon, C. \& Ehrenberg, A. S. C. (1970) Brand image and brand usage. Journal of Marketing Research, 7(3), pp. 307-314.

Bitner, M. J., Faranda, W. T., Hubbert, A. R. \& Zeithaml, V. A. (1997) Customer contributions and roles in service delivery. International Journal of Service Industry Management, 8(3), pp. 193. 
Chell, E. \& Pittaway, L. (1998) A study of entrepreneurship in the restaurant and cale industry: exploratory work using the critical incident technique as a methodology. International Journal of Hospitality Management, 17, pp. 23-32.

Chizzotti, A. (2006). Pesquisa em ciências humanas e sociais. Cortez: São Paulo.

Cougo, R. L. (2001) Satisfação de consumidores: um estudo em escolas de informática na cidade de Bagé. Dissertação (Mestrado em Administração) - Programa de Pós-Graduação em Administração da Universidade Federal do Rio Grande do Sul. Disponível em: http://hdl.handle.net/10183/1765. Acesso em 14 de janeiro de 2013.

Dolich, I. J. (1969) Congruence relationships between self images and product brands. Journal of Marketing Research, 6(1), pp. 80-84.

Flanagan, J. C. (1973) A técnica do incidente crítico. Arq. Bras. Psicol. Aplicad, 25(2), pp. 99-141.

Gupta, S. \& Vajic, M. (2000) The contextual and dialectical nature of experience, new service development, creating memorable experiences. Sage, New York.

Hirschman, E. C. \& Holbrook, M. B. (1982) Hedonic consumption: emerging concepts, methods and propositions. Journal of Marketing, 46, pp. 92-101.

Hirschman, E. C. (1986). The creation of product symbolism. Advances in Consumer Research, 13(1), pp. 327-331.

Holbrook, M. B \& Hirschman, E. C. (1982) The experiential aspects of consumption: consumer fantasies, feelings, and fun. Journal of Consumer Research, 9, pp. 132-140.

Imankhan, N., Fakharyan, M. \& Feyzabadi, S. (2012) The effect of customer-to-customer interactions on satisfaction with the firm, loyalty to the firm and firm word-of-mouth: the case of Iran Air Company. African Journal of Business Management, 6(39), pp. 10427-10437.

Izberk-Bilgin, E. (2012) Infidel brands: unveiling alternative meanings of global brands at the nexus of globalization, consumer culture, and Islamism. Journal of Consumer Research, 39(4), pp. 663-687.

Keller, K. L. \& Lehmann, D. (2006) Brands and branding: research findings and future priorities. Marketing Science, 25, pp. 740-759.

Keller, K. K. \& Machado, M. (2006) Gestão estratégica de marcas. Pearson Prentice-Hall: São Paulo.

Keller, K. L. (1993) Conceptualizing, measuring, and managing customer-based brand equity. Journal of Marketing, 57, pp. 1-22.

Lee, D. H. (1990) Symbolic interactionism: some implications for consumer self-concept and product symbolism research. Advances in Consumer Research, 17(1), pp. 386-393.

Leite, R. C., Winck, C. A. \& Zonin, V. J. (2012) A influência do estrangeirismo no processo de construção da marca no agronegócio. Brazilian Business Review - BBR, 9(1), pp. 110-133. 
Puligadda, S., Ross Jr., W. T. \& Grewal, R. (2012) Individual differences in brand schematicity. Journal of Marketing Research, 49(1), pp. 115-130.

Pyun, D. Y., Kwon, H. H. \& Lee, C.-W. (2011) The influences of perceived brand quality and ethnocentrism on consumption patterns of a global sports brand: the case of Korean college students. International Journal of Sports Marketing \& Sponsorship, 13(1), pp. 23-37.

Raj, S. P. (1985) Striking a balance between brand "popularity" and brand loyalty. Journal of Marketing, 49(1), pp. 53-59.

Schembri, S., Merrilees, B. \& Kristiansen, S. (2010) Brand consumption and narrative of the self. Psychology \& Marketing, 27(6), pp. 623-637.

Schenk, C. T. \& Holman, R. H. (1980) A sociological approach to brand choice: the concept of situational self image. Advances in Consumer Research, 7, pp. 610-614.

Schmitt, B. H., Zarantonello, L. \& Brakus, J. J. (2009) Brand experience: What is it? How is it measured? Does it affect loyalty? Journal of Marketing, 73(3), pp. 52-68.

Sheth, J. N., Park, C. W. (1974) A theory of multidimensional brand loyalty. Advances in Consumer Research, 1, pp. 449-459.

Silva, A. (2005) A vivência de conflitos entre a prática gerencial e as relações em família. Dissertação (Mestrado em Engenharia de Produção) - Universidade Federal de Santa Catarina, Programa de PósGraduação em Engenharia de Produção, Florianópolis.

Artigo recebido em: 30/05/2014. Artigo aprovado em: 25/03/2015. 